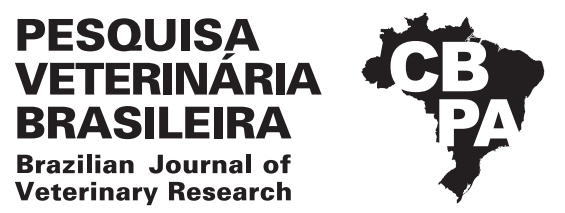

Pesq. Vet. Bras. 38(8):1484-1490, agosto 2018 DOI: 10.1590/1678-5150-PVB-5291

Artigo Original

Animais de Produção/Livestock Diseases

ISSN 0100-736X (Print)

ISSN 1678-5150 (Online)

\title{
Infecção pelo vírus influenza A em suínos no sul de Moçambique $^{1}$
}

\author{
Cláudio J.M. Laisse ${ }^{2,3 *}$, Matheus V. Bianchi², Paula R. Pereira² ${ }^{2}$ Cíntia De Lorenzo², \\ Saulo P. Pavarini ${ }^{2}$ e David Driemeier ${ }^{2}$
}

\begin{abstract}
Laisse C.J.M., Bianchi M.V., Pereira P.R., De Lorenzo C., Pavarini S.P. \& Driemeier D. 2018. [Influenza A virus infection in pigs in southern Mozambique.] Infecção pelo vírus influenza A em suínos no sul de Moçambique. Pesquisa Veterinária Brasileira 38(8):1484-1490. Setor de Patologia Veterinária, Departamento de Patologia Clínica Veterinária, Faculdade de Veterinária, Universidade Federal do Rio Grande do Sul, Av. Bento Gonçalves 9090, Porto Alegre, RS 91540-000, Brazil. E-mail: claudiolaisse@yahoo.com.br

Swine influenza (SI) is an acute and highly contagious disease of the respiratory tract of pigs caused by influenza A virus (IAV). The disease causes economic losses in swine production and is of great public importance for its zoonotic potential. The aim of the present study was to report IAV infection in pigs from Mozambique and characterize the anatomopathological and immunohistochemical features of associated lung lesions. Lungs from 457 slaughtered pigs were subjected to gross evaluation and $38(8.3 \%)$ lungs with cranioventral consolidation were collected from a slaughterhouse in Matola City, southern Mozambique. Areas of consolidation in each lung lobe were classified in 4 grades according to the lesion extension. Samples with consolidated lung tissue were examined for histopathology and immunohistochemistry (IHC) for the presence of IAV, Porcine circovirus type 2 (PCV2) and Mycoplasma hyopneumoniae antigens. The lungs had multifocal to coalescing areas of consolidation observed most frequently in the cranial, middle, and accessory lobes. The lesions involved mainly one or three pulmonary lobes and grade 1 and 2 lesions were the most frequent. The main histopathological findings were necrotizing bronchiolitis (23/38), alveolar neutrophil infiltration (24/38), type II pneumocytes hyperplasia (26/38), peribronchiolar lymphoid tissue hyperplasia $(28 / 38)$ and interstitial mononuclear cells infiltrate (29/38). Immunohistochemistry revealed positive staining in $84.3 \%$ $(32 / 38)$ of the samples and IAV nucleoprotein was present in the nucleus of bronchial and bronchiolar epithelial cells and alveolar macrophages. Positive IHC pigs were from Matutuine district (5/32), Moamba district (2/32), Namaacha district (21/32), Boane district (3/32) and Matola city (1/32). All lung samples were immunohistochemically negative for PCV2 and Mycoplasma hyopneumoniae. These results demonstrate that IAV is a cause of pneumonia in pigs in Mozambique.
\end{abstract}

INDEX TERMS: Swine diseases, influenza A virus, immunohistochemistry, pulmonary consolidation, Mozambique, viral diseases, viroses.

RESUMO.- A influenza suína (IS) é uma doença aguda e altamente contagiosa do trato respiratório de suínos, causada pelo vírus influenza A (VIA). A doença provoca perdas

\footnotetext{
${ }^{1}$ Recebido em 7 de agosto de 2017.

Aceito para publicação em 29 de agosto de 2017.

${ }^{2}$ Setor de Patologia Veterinária, Departamento de Patologia Clínica Veterinária, Faculdade de Veterinária, Universidade Federal do Rio Grande do Sul (UFRGS), Av. Bento Gonçalves 9090, Porto Alegre, RS 91540-000, Brasil.*Autor para correspondência: claudiolaisse@yahoo.com.br

${ }^{3}$ Secção de Anatomia Patológica, Faculdade de Veterinária, Universidade Eduardo Mondlane (UEM), Avenida de Moçambique Km 15, Maputo, Moçambique.
}

econômicas na suinocultura e também, tem importância na saúde pública devido ao seu potencial zoonótico. 0 objetivo deste trabalho foi relatar a infecção pelo VIA em suínos de Moçambique e realizar a caracterização anatomopatológica e imuno-histoquímica (IHQ) das lesões pulmonares associadas. Pulmões de 457 suínos abatidos foram avaliados e coletados $38(8,3 \%)$ pulmões de suínos com áreas de consolidação pulmonar em um abatedouro na cidade da Matola, no Sul de Moçambique. As áreas de consolidação em cada lobo pulmonar foram classificadas em 4 graus de acordo com a extensão da lesão. Amostras de pulmões com consolidação 
foram submetidas ao exame histopatológico e IHQ para a detecção de antígenos do VIA, Circovírus suíno tipo 2 (PCV2) e Mycoplasma hyopneumoniae. Os pulmões coletados apresentaram áreas multifocais ou coalescentes de consolidação pulmonar, frequentemente, observadas nos lobos craniais, mediais e acessório. Estas lesões acometiam principalmente um ou três lobos pulmonares e as lesões de grau 1 e 2 foram as mais frequentes. As principais lesões histopatológicas observadas foram bronquiolite necrotizante (23/38), infiltrado de neutrófilos nos alvéolos (24/38), hiperplasia de pneumócitos tipo II (26/38), hiperplasia de tecido linfoide peribronquiolar (28/38), e pneumonia intersticial mononuclear (29/38). No exame de IHQ, antígenos do VIA foram detectados em $84.3 \%$ (32/38) dos pulmões com pneumonia, e a nucleoproteína do vírus foi visualizada, no núcleo de células epiteliais de brônquios e bronquíolos e em macrófagos alveolares. Suínos positivos para o VIA na IHQ eram provenientes do distrito de Matutuine (5/32), distrito da Moamba (2/32), distrito de Namaacha (21/32), distrito de Boane (3/32) e Cidade da Matola (1/32). Todas as amostras foram negativas para PCV2 e Mycoplasma hyopneumoniae pelo exame de IHQ. Os resultados demonstram que o VIA está presente e é causa de pneumonia em suínos em Moçambique.

TERMOS DE INDEXAÇÃO: Doenças de suínos, vírus influenza A, imuno-histoquímica, consolidação pulmonar, Moçambique, suínos, viroses.

\section{INTRODUÇÃO}

As doenças infecciosas respiratórias de suínos são um dos principais problemas sanitários na suinocultura tecnificada e são causadas por agentes virais e bacterianos que fazem parte do complexo de doenças respiratórias dos suínos (CDRS) (Van Alstine 2012). Um dos agentes envolvidos no CDRS é o vírus influenza A (VIA), um vírus RNA de cadeia simples negativa, da Família Orthomyxoviridae (Harms et al. 2002, Kothalawala et al. 2006, Van Alstine 2012, Van Reeth et al. 2012). 0 VIA pode infectar vários hospedeiros, incluindo suínos e humanos (Dandagi \& Byahatti 2011). A influenza suína (IS) é uma doença aguda e altamente contagiosa, de distribuição mundial, que causa importante impacto econômico na suinocultura (Kothalawala et al. 2006).

Os principais subtipos do VIA que infectam suínos são H1N1, H1N2 e H3N2 (Choi et al. 2003, Janke 2014, Lyoo et al. 2014, Vincent et al. 2014). Contudo, os suínos também podem se infectar com outros subtipos do VIA, originários de humanos e aves, o que os torna um hospedeiro importante na epidemiologia da infecção pelo vírus (Ito et al. 1998). A transmissão natural do VIA entre suínos ocorre através do contato direto com secreções de animais infectados ou por aerossóis, e provoca um quadro clínico agudo caracterizado por febre, respiração abdominal, descarga nasal, tosse e depressão (Jung et al. 2005, Rajão et al. 2013, Vincent et al. 2014, Caswell \& Williams 2016). A doença acomete suínos de qualquer idade, causa alta morbidade, porém, baixa taxa de mortalidade (Van Reeth et al. 2012). 0 diagnóstico presuntivo de IS pode ser obtido com base nos sinais clínicos e lesões macroscópicas e histológicas características da infecção pelo vírus, contudo, o diagnóstico definitivo é baseado no isolamento viral, detecção de antígenos e/ou material genético do vírus (Van Reeth et al. 2012, Schaefer et al. 2013).
Em Moçambique, a população suína é estimada em 1.588,325 (INE 2016) e as produções em sua maior parte são pequenas (com menos de 50 suínos) (INE 2001,2011) e fazem criação em sistema extensivo. Contudo, há uma tendência em aumentar o número de médias propriedades (INE 2001, 2011), que criam os suínos em confinamento, o que favorece a ocorrência de doenças respiratórias (Mastin et al. 2011). Contrariamente ao verificado na Europa, Ásia e Américas, em países da África, pesquisas sobre a infecção pelo VIA em suínos são escassas ou inexistentes (Meseko et al. 2013). Em Moçambique, não há trabalhos publicados que descrevam a ocorrência deste vírus na população suína. 0 objetivo desse trabalho é relatar a ocorrência de infecção pelo VIA em suínos de Moçambique e realizar uma caracterização anatomopatológica e imuno-histoquímica das lesões pulmonares.

\section{MATERIAL E MÉTODOS}

Amostras. Pulmões com alterações macroscópicas de consolidação pulmonar foram coletadas de suínos, durante o abate, em um abatedouro localizado na cidade da Matola, Província de Maputo, no sul de Moçambique ( $25^{\circ} 55^{\prime} 26^{\prime}$ S, 32 27' 57” E), no período de dezembro de 2014 a fevereiro de 2015 e dezembro de 2015 a fevereiro de 2016. Este abatedouro de suínos é o maior na região sul de Moçambique e abate suínos provenientes de vários distritos desta região.

Exame macroscópico. Os suínos abatidos não foram submetidos à avaliação clínica para detectar sinais clínicos de doença respiratória. Pulmões de todos os suínos abatidos nos dias em que foram feitas as coletas foram submetidos a avaliação visual e palpação para detectar alteração de cor e consistência nos sete lobos pulmonares: cranial esquerdo (CRE) e direito (CRD), medial esquerdo (ME) e direito (MD), acessório (A), caudal esquerdo (CAE) e direito (CAD) (Van Alstine 2012).

Para pulmões que apresentaram consolidação pulmonar, a porcentagem da área da lesão em cada lobo foi estimada com base na divisão imaginária dos lobos em quatro partes iguais e classificada segundo o método de Madec e Kobisch (Lyoo et al. 2014). A porcentagem da área com consolidação em cada lobo foi expressa nos seguintes graus: grau 0 , sem lesão; grau 1 , pneumonia discreta ( 1 a $25 \%$ do lobo pulmonar); grau 2, pneumonia moderada (26 a $50 \%$ do lobo pulmonar); grau 3, pneumonia acentuada (51 a $75 \%$ do lobo pulmonar); e grau 4, pneumonia muito acentuada (76 a 100\% do lobo pulmonar).

A porcentagem da área de consolidação por lobo pulmonar, origem e peso vivo do suíno foi registrada. A idade dos suínos abatidos não estava disponível nos registos do abatedouro. Foi feita uma visita técnica a granja que apresentou maior número de casos de pneumonia com o objetivo de ver o sistema produtivo aplicado.

Histopatologia e exame de imuno-histoquímica. As amostras de pulmões com consolidação foram fixadas em solução de formalina tamponada a $10 \%$ por 48 horas, processadas rotineiramente para histologia, incluídas em blocos de parafina, cortadas a $3 \mu \mathrm{m}$ e coradas com hematoxilina e eosina (HE).

Para detectar antígenos do VIA, todas as amostras de pulmão com pneumonia foram submetidas à técnica de imuno-histoquímica (IHQ). A recuperação antigênica foi obtida com protease XIV por 25 minutos a $37^{\circ} \mathrm{C}$. A inibição de ligações não específicas foi realizada com leite desnatado $5 \%$ durante 15 minutos a temperatura ambiente (TA). As lâminas foram incubadas overnight em anticorpo primário monoclonal anti-IA na diluição de 1:500 (Millipore, Billerica, MA, USA). Foi utilizado como anticorpo secundário o polímero MACH 4 
Universal HRP-Polymer (Biocare Medical, Concord, CA). A reação foi revelada com o cromógeno 3'3-diaminobenzidina (DAB, Dako). As lâminas foram contra-coradas com hematoxilina de Harris. Como controle negativo, cortes de pulmão foram incubados com solução fosfatada tamponada (PBS), ao invés de anticorpo primário e para controle positivo foram empregados cortes de pulmão positivos para o VIA (Watanabe et al. 2012).

As amostras de pulmão foram igualmente submetidas a exame de IHQ para Circovírus suíno tipo 2 (PCV2) empregando um anticorpo policlonal anti-PCV2 (Iowa State University, USA) na diluição de 1:1000 (Zlotowski et al. 2008) e para Mycoplasma hyopneumoniae usando um antisoro autoimune anti-Mycoplasma hyopneumoniae, gentilmente cedido por Nelson Morés (CNPSA/Embrapa), na diluição de 1:200 (Almeida et al. 2012).

\section{RESULTADOS}

\section{Exame macroscópico}

No período em que foram realizadas as coletas de amostras, foram abatidos e avaliados 457 suínos, (mínimo de seis e máximo de 47 suínos abatidos/dia) provenientes da Cidade de Maputo e Províncias de Maputo (distritos de Boane, Matola, Manhiça, Matutuine, Moamba e Namaacha,) e Gaza (distritos de Chibuto e Xai-Xai). Os suínos abatidos eram de raças locais (raça Landim) e raças exóticas, principalmente, Large White e Landrace. Trinta e oito $(8,3 \%)$ suínos apresentaram áreas de consolidação, em pelo menos um lobo pulmonar, e estas, eram multifocais ou coalescentes, bem delimitadas, avermelhadas a acinzentadas e com consistência aumentada em relação ao parênquima pulmonar normal (Fig.1). Consolidação pulmonar foi detectada afetando um $(31,6 \%)$, dois $(7,9 \%)$, três $(26,3 \%)$, quatro $(7,9 \%)$, cinco $(5,3 \%)$, seis $(10,5 \%)$ e sete $(10,5 \%)$ lobos. Os lobos MD (76,3\%) e ME $(57,9 \%)$ foram

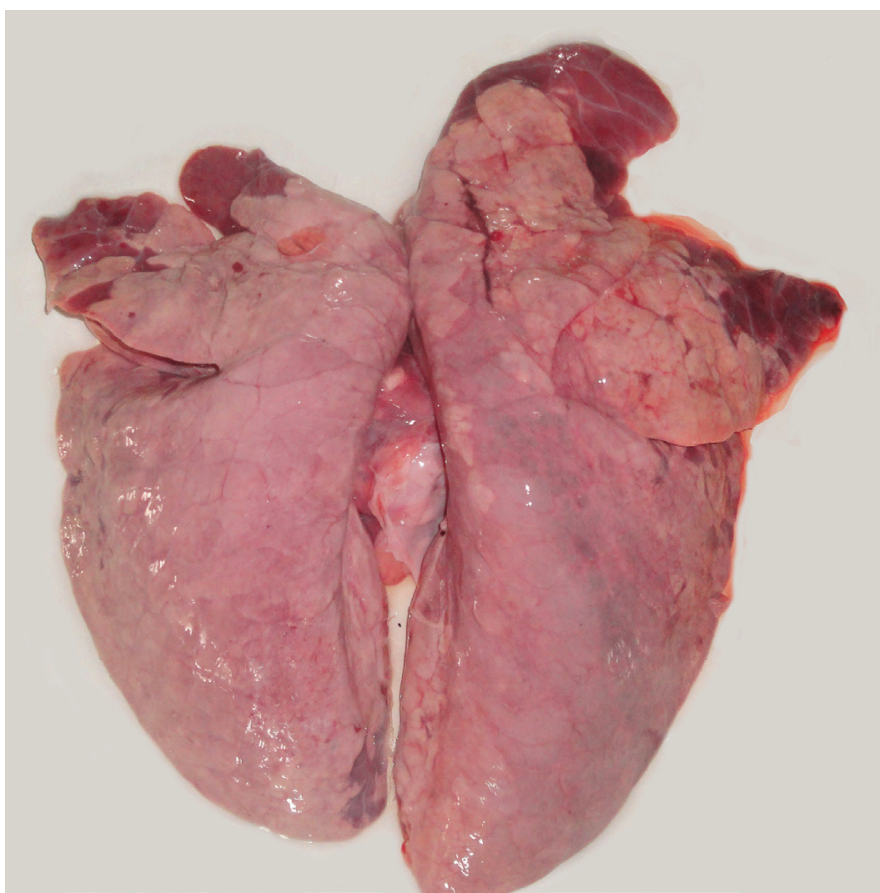

Fig.1. Pneumonia pelo vírus influenza A em suínos de abate. Pulmão não colabado, com áreas de consolidação cranioventral nos lobos cranial esquerdo (grau 1), cranial direito (grau 2), medial esquerdo (grau 1) e medial direito (grau 2). os mais acometidos e apresentaram maior porcentagem de lesões de graus 2, 3 e 4, enquanto os lobos CAD (26,3\%) e CAE $(26,3 \%)$ foram os menos afetados, e, quando acometidos, apresentaram lesões de graus 1 e 2 (Quadro 1). Os pulmões com consolidação geralmente apresentavam-se não colapsados e alguns tinham secreção mucopurulenta no interior de brônquios e bronquíolos e edema.

0 peso vivo dos suínos que apresentaram consolidação pulmonar (n=38) variava de 5 a $120 \mathrm{~kg}$ (média de 64,3 kg). Em relação à origem, 13,2\% (5/38) eram do distrito de Matutuine, 5,3\% (2/38) do distrito de Moamba, 68,4\% (26/38) do distrito de Namaacha, 2,6\% (1/38) do distrito de Chibuto, $7,9 \%$ (3/38) do distrito de Boane e 2,6\% (1/38) da cidade da Matola. Todos os suínos com pneumonia, provenientes do distrito de Namaacha $(n=26)$ eram de uma granja comercial e foram abatidos entre os meses de dezembro de 2014 e fevereiro de 2015. Durante visita técnica a esta granja, constatou-se que aplicava um sistema de criação semi-intensivo.

\section{Histopatologia}

Foram observadas lesões microscópicas com graus de severidade distintos, sendo que, as lesões mais frequentes foram bronquiolite necrotizante (23/38) (Fig.2A) infiltrado de neutrófilos nos alvéolos (24/38), hiperplasia de pneumócitos tipo II (26/38), hiperplasia de tecido linfoide peribronquiolar (BALT) (28/38), e pneumonia intersticial mononuclear (29/38). 0 infiltrado intersticial era constituído, principalmente, por linfócitos e plasmócitos, que eram, frequentemente, observados no espaço perivascular e peribronquiolar. Alguns pulmões apresentaram ainda bronquiolite obliterante (Fig.2B), edema alveolar e intersticial, pleurite, hiperemia, áreas de atelectasia e enfisema.

\section{Imuno-histoquímica}

Antígenos do VIA foram detectados em 32/38 dos pulmões de suínos com pneumonia. Os suínos positivos eram de granjas dos distritos de Matutuine (5/32), distrito de Moamba (2/32), distrito de Namaacha (21/32), distrito de Boane (3/32) e Cidade da Matola (1/32) (Fig.3). A imunomarcação foi visualizada no núcleo de células epiteliais de bronquíolos (Fig.2C) e/ou brônquios (25/32, 78\%) (Fig.2D), ou em macrófagos localizados nos septos alveolares ou na luz dos alvéolos (27/32, 84,4\%). Em 20/32 (62,5\%) das amostras, a imunomarcação foi concomitante em células epiteliais de

Quadro 1. Distribuição percentual dos diferentes graus de lesão nos lobos dos 38 pulmões de suínos que apresentaram consolidação

\begin{tabular}{crrrrrrr}
\hline \multirow{2}{*}{ Grau } & \multicolumn{6}{c}{ \% de casos por grau de pneumonia em cada lobo pulmonar } \\
\cline { 2 - 7 } & CRD & \multicolumn{1}{c}{ CRE } & MD & ME & \multicolumn{1}{c}{ A } & CDE & CDD \\
\hline 0 & 54,1 & 56,8 & 24,3 & 40,5 & 51,4 & 73 & 73 \\
1 & 13,5 & 18,9 & 21,6 & 8,1 & 18,9 & 24,3 & 24,3 \\
2 & 18,9 & 10,8 & 18,9 & 27 & 8,1 & 2,7 & 2,7 \\
3 & 2,7 & 2,7 & 18,9 & 8,1 & 10,8 & 0,0 & 0,0 \\
4 & 10,8 & 10,8 & 16,2 & 16,2 & 10,8 & 0,0 & 0,0 \\
Total & 100 & 100 & 100 & 100 & 100 & 100 & 100
\end{tabular}

Lobos pulmonares: $\mathrm{CRD}=$ cranial direito, $\mathrm{CRE}=$ cranial esquerdo $\mathrm{MD}=$ medial direito, $\mathrm{ME}=$ medial esquerdo, $\mathrm{A}=$ acessório, $\mathrm{CAD}=$ caudal direito, $\mathrm{CAE}=$ caudal esquerdo. 


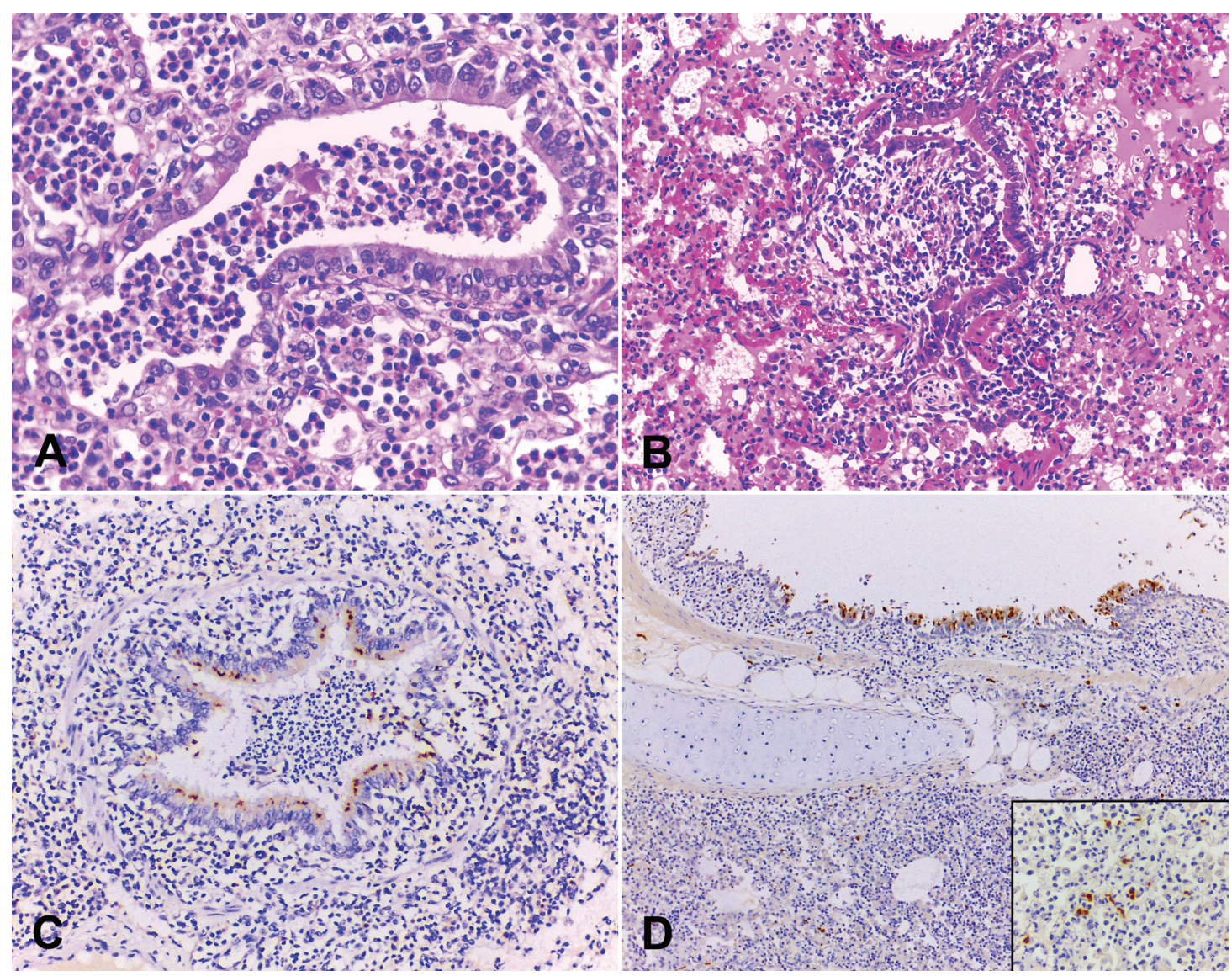

Fig.2. Pneumonia pelo vírus influenza A em suínos de abate. (A) Bronquiolite necrotizante, com infiltrado de neutrófilos no lúmen de bronquíolo e nos espaços alveolares. HE, obj. 40x. (B) Bronquiolite obliterante, infiltrado de linfócitos peribronquiolar e edema alveolar difuso. HE, obj.20x. (C) Imunomarcação para o VIA em células epiteliais de bronquíolo. IHQ, obj.20x. (D) Imunomarcação para o VIA em células epiteliais de brônquio e marcação multifocal em macrófagos no interstício. A figura menor mostra em detalhe a imunomarcação nos macrófagos alveolares. IHQ obj.10x (detalhe = 40x).

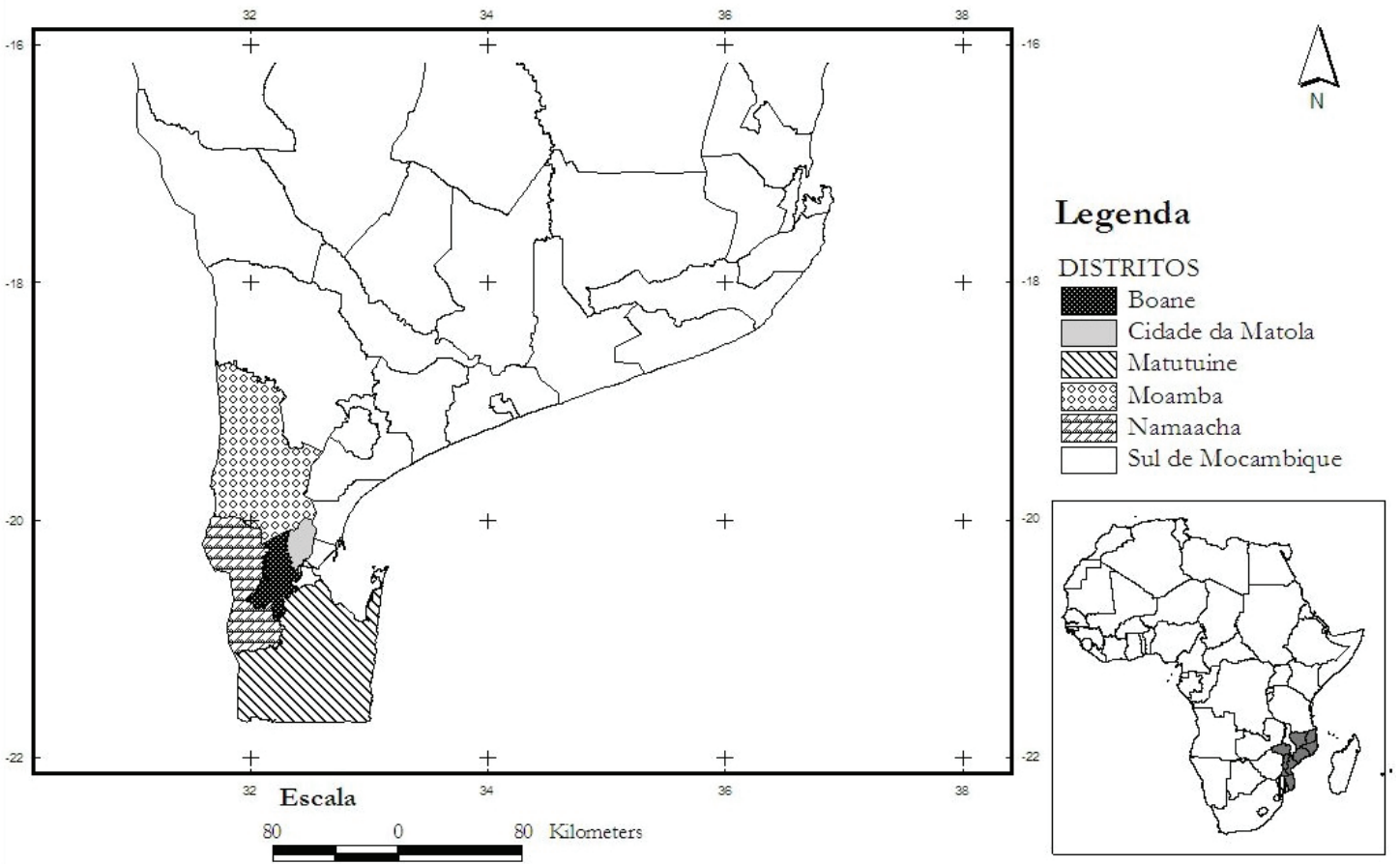

Fig.3. Mapa de Moçambique evidenciando os cinco distritos de proveniência dos suínos positivos para o VIA no exame de imuno-histoquímica. 
bronquíolos e/ou brônquios e nos macrófagos alveolares (Fig.2D). Onze amostras também apresentaram imunomarcação no epitélio de glândulas bronquiais. Todos os pulmões que apresentaram pneumonia $(\mathrm{n}=38)$ foram negativos no exame de IHQ para PCV2 e M. hyopneumoniae.

\section{DISCUSSÃO}

Este trabalho descreve a frequência e severidade de pneumonias, achados anatomopatológicos e imuno-histoquímicos associados à infecção pelo VIA em pulmões de suínos em Moçambique. A pneumonia é a lesão pulmonar mais frequente em suínos ao abate (Fraile et al. 2010, Fablet et al. 2011, Van Alstine 2012). A frequência de pneumonias observada nesse estudo $(8,3 \%)$ é menor em relação à registada em países como França $(50,8 \%)$ (Fablet et al. 2011), Espanha $(55,7 \%)$ (Fraile et al. 2010) e Nova Zelândia (63,4\%) (Stark et al. 1998). Isso, possivelmente, se deve ao fato de que em Moçambique, a suinocultura ser, principalmente, extensiva e semi-intensiva, com suínos criados livres ou em baias não totalmente fechadas e com pouca densidade animal. No presente estudo, a maior frequência de pneumonias foi observada em uma granja do distrito de Namaacha 68\% (26/38) que faz a criação de suínos em confinamento, num sistema de criação semi-intensivo. A ocorrência de pneumonias associada ao sistema de criação aplicado nessa granja corrobora o fato de que granjas que criam os suínos em confinamento e com maior número de suínos por baia são mais suscetíveis de registar doenças respiratórias (Mastin et al. 2011).

As áreas de consolidação pulmonar geralmente apresentavam padrão cranioventral e envolveram, principalmente, os lobos craniais, mediais e acessório. Os principais diagnósticos diferenciais para este padrão de lesão incluem a infecção pelo VIA, Mycoplasma hyopneumoniae e PCV2 associado à Pasteurella multocida (Fraile et al. 2010, Gauger et al. 2012). 0 aspecto macroscópico típico de pneumonia por influenza em suínos é de áreas vermelhas, ligeiramente deprimidas (atelectasia) e firmes (consolidação), afetando áreas extensas da região cranioventral do pulmão, podendo se estender às áreas caudais em lóbulos isolados, dando o aspecto de "tabuleiro de xadrez" (Pereda et al. 2010, Schaefer et al. 2013). No presente trabalho, este padrão de lesão foi observado em vários pulmões, pelo que, a confirmação da infecção pelo VIA foi feito através da visualização de antígenos virais associados a lesão pulmonar (Van Reeth et al. 2012, Schaefer et al. 2013).

Uma das principais lesões histológicas observadas nos suínos desse estudo foi a bronquiolite necrotizante. Esse tipo de lesão histopatológica é característica da infecção aguda pelos subtipos do VIA adaptados a suínos (H1N1, H1N2 e H3N2) e pelo VIA H1N1pdm2009 (Sreta et al. 2009, Pereda et al. 2010, Lyoo et al. 2014). Assim como descrito em outros estudos (Sreta et al. 2009, Watanabe et al. 2012, Rajão et al. 2013), no exame de IHQ, antígenos de VIA foram visualizados no núcleo de células epiteliais de brônquios e bronquíolos e/ou em macrófagos alveolares. Em 11 amostras de pulmão, imunomarcação para a nucleoproteína do VIA, também foi observada no epitélio de glândulas bronquiais, achado também descrito em suínos (Rajão et al. 2013) e em humanos (Nakajima et al. 2012) infectados pelo VIA H1N1pdm2009. 0 fato de a imunomarcação ter sido frequente nos macrófagos alveolares e alguns pulmões terem apresentado número reduzido de células positivas, associado à alta frequência de pneumonia intersticial linfoplasmocitária, hiperplasia de BALT e hiperplasia de pneumócitos tipo II, sugere que a maioria dos suínos avaliados no presente estudo apresentava infecção subaguda pelo VIA (Valheim et al. 2011, Caswell \& Williams 2016). Adicionalmente, três suínos com resultado negativo na IHQ para o VIA apresentaram lesões histopatológicas sugestivas de infecção por este vírus. A marcação do VIA na IHQ ocorre, principalmente, na fase aguda da doença (um a cinco dias após a infecção) e a quantidade de antígenos no pulmão está reduzida a partir do sétimo dia após a infecção (Jung et al. 2005, Gauger et al. 2012, Lyoo et al. 2014). Antígenos do VIA foram detectados em suínos com peso vivo entre 5 e $120 \mathrm{~kg}$, o que demonstra que este vírus pode infectar suínos de diferentes faixas etárias, assim como descrito por Watanabe et al. (2012) e Rajão et al. (2013).

Suínos infectados pelo VIA geralmente apresentam coinfecção com outros patógenos do CDRS (Harms et al. 2002, Choi et al. 2003, Valheim et al. 2011, Rajão et al. 2013). Choi et al. (2003) detectaram o VIA em 636 (22,2\%) amostras de pulmões de suínos, sendo que, a infecção simples pelo VIA foi observada em 89 (3,1\%) amostras, enquanto que, coinfecção entre o VIA e Pasteurella multocida, Mycoplasma hyopneumoniae, vírus da síndrome reprodutiva e respiratória suína (PRRSV) e PCV2 ocorreu, respectivamente, em 148 (5,2\%), 122 (4,3\%), $109(3,8 \%)$ e $54(1,9 \%)$ amostras. No presente estudo, todos os pulmões com pneumonia foram negativos no exame de IHQ para Mycoplasma hyopneumoniae e PCV2. As amostras não foram submetidas ao cultivo bacteriano nem a pesquisa para o PRRSV, contudo, não se descarta a possibilidade de ter havido coinfecção entre o VIA e agentes bacterianos, já que, vários pulmões apresentaram broncopneumonia supurativa sugestiva de infecção bacteriana. Todavia, histologicamente, na infecção por PRRSV não há envolvimento do epitélio de bronquíolos (Caswell \& Williams 2016), o que pode auxiliar na diferenciação da infecção pelo VIA. O PRRSV ainda não foi descrito em Moçambique.

Antígenos do VIA foram detectados em suínos provenientes de vários distritos, o que sugere que este vírus está disseminado na população suína em Moçambique. 0 fato de os suínos da granja de Namaacha que apresentaram pneumonia e imunomarcação para o VIA terem sido abatidos num período de dois meses, sugere que o abate ocorreu num período em que o lote abatido tinha sido afetado por um surto de IS. Portanto, devem ser tomadas medidas de controle da influenza suína, principalmente, nas granjas comerciais. O VIA pode infectar humanos, e as pessoas que trabalham com suínos são o grupo mais suscetível (Dandagi \& Byahatti 2011). Em Moçambique, foram confirmados casos clínicos e óbitos humanos associados à infecção pelo vírus da influenza A/ H1N1/2009 pandêmico (WHO 2009), contudo, neste país, não há dados que confirmam a transmissão do VIA entre humanos e suínos. Na África, o vírus da influenza A/H1N1/2009 pandêmico já foi detectado em suínos, em países como Camarões (Njabo et al. 2012), Togo (Ducatez et al. 2015) e Gana (Adeola et al. 2015).

Os resultados deste trabalho demonstram que o VIA é causa de pneumonia em suínos em Moçambique. Recomenda-se a realização de estudos com o objetivo de caracterizar os subtipos do VIA circulantes, seu impacto na suinocultura e na saúde pública nesse país.

Agradecimentos.- Ao Conselho Nacional de Desenvolvimento Científico e Tecnológico (CNPq), Brasil e The World Academy of Sciences (TWAS) - a 
bolsa de doutorado do primeiro autor foi financiada no âmbito do edital "CNPq-TWAS Fellowships Programme 2012". A direção e funcionários do abatedouro por terem tornado possível à coleta de amostras. Aos técnicos do sector de Anatomia Patológica da Faculdade de Veterinária da Universidade Eduardo Mondlane pelo apoio no processamento histopatológico das amostras.

\section{REFERÊNCIAS}

Adeola 0.A., Olugasa B.O. \& Emikpe B.O. 2015. Detection of pandemic strain of influenza virus (A/H1N1/pdm09) in pigs, West Africa: implications and considerations for prevention of future influenza pandemics at the source. Infect. Ecol. Epidemiol. 5(1):30227. <http://dx.doi.org/10.3402/ iee.v5.30227><PMid:26715380>

Almeida P.R., Andrade C.P., Almeida L.L., Oliveira L.G.S., Castro L.A., Zlotowski P., Silva S.C. \& Driemeier D. 2012. Nested-PCR for the detection of Mycoplasma hyopneumoniae in bronchial alveolar swabs, frozen tissues and formalinfixed paraffin-embedded swine lung samples: Comparative evaluation with immunohistochemical findings and histological features. Pesq. Vet. Bras. 32(8):715-720. <http://dx.doi.org/10.1590/S0100-736X2012000800006>

Caswell J.L. \& Williams K.J. 2016. Respiratory system, p.526-527. In: Maxie M.G. (Ed.), Jubb, Kennedy and Palmer's Pathology of Domestic Animals. Vol.2. 6th ed. Elsevier, St Louis. <http://dx.doi.org/10.1016/B978-07020-5318-4.00011-5>.

Choi Y.K., Goyal S.M. \& Joo H.S. 2003. Retrospective analysis of etiologic agents associated with respiratory diseases in pig. Can. Vet. J. 44(9):735737. <PMid:14524628>

Dandagi G.L. \& Byahatti S.M. 2011. An insight into the swine-influenza A (H1N1) virus infection in humans. Lung India 28(1):34-38. <http://dx.doi. org/10.4103/0970-2113.76299><PMid:21654984>

Ducatez M.F., Awoume F. \& Webby R.J. 2015. Influenza A(H1N1)pdm09 virus in pigs, Togo, 2013. Vet. Microbiol. 177(1/2):201-205. <http://dx.doi. org/10.1016/j.vetmic.2015.02.028><PMid:25778544>

Fablet C., Dorenlor V., Eono F., Eveno E., Madec F. \& Rose N. 2011. Prevalence of macroscopic lung lesions in slaughter pigs in France. Proceedings of the XV International Congress of the International Society for Animal Hygiene, Vienna, Austria, p.47-49. (Resumo)

Fraile L., Alegre A., López-Jiménez R., Nofrarías M. \& Segalés J. 2010. Risk factors associated with pleuritis and cranio-ventral pulmonary consolidation in slaughter-aged pigs. Vet. J. 184(3):326-333.<http://dx.doi.org/10.1016/j. tvjl.2009.03.029><PMid:19527939>

Gauger P.C., Vincent A.L., Loving C.L., Henningson J.N., Lager K.M., Janke B.H., Kehrli Junior M.E. \& Roth J.A. 2012. Kinetics of lung lesion development and pro-inflammatory cytokine response in pigs with vaccine-associated enhanced respiratory disease induced by challenge with pandemic (2009) A/H1N1 influenza virus. Vet. Pathol. 49(6):900-912. <http://dx.doi. org/10.1177/0300985812439724><PMid:22461226>

Harms P.A., Halbur P.G. \& Sorden S.D. 2002. Three cases of porcine respiratory disease complex associated with porcine circovirus type 2 infection. J. Swine Health Prod. 10:27-30.

INE 2001. Censo Agro-Pecuário 1999-2000: apresentação sumária dos resultados, quadros e gráficos, Moçambique. Instituto Nacional de Estatística, Moçambique, p.83-89.

INE 2011. Censo Agro-Pecuário 2009-2010: resultados preliminares, Moçambique. Instituto Nacional de Estatística, Moçambique, p.85-89.

INE 2016. Anuário Estatístico. Moçambique. Instituto Nacional de Estatística de Moçambique, p.54. Disponível em <www.ine.gov.mz/estatisticas/ publicacoes/anuario/nacionais/anuario-estatistico-2015> Acesso em 20 out. 2016.

Ito T., Couceiro J.N., Kelm S., Baum L.G., Krauss S., Castrucci M.R., Donatelli I., Kida H., Paulson J.C., Webster R.G. \& Kawaoka Y. 1998. Molecular basis for the generation in pigs of influenza A viruses with pandemic potential. J. Virol. 72(9):7367-7373. <PMid:9696833>

Janke B.H. 2014. Influenza A virus Infections in swine: pathogenesis and diagnosis. Vet. Pathol. 51(2):410-426.<http://dx.doi.org/10.1177/0300985813513043> $<$ PMid:24363301>

Jung K., Ha Y. \& Chae C. 2005. Pathogenesis of swine influenza virus subtype H1N2 infection in pigs. J. Comp. Pathol. 132(2/3):179-184.<http://dx.doi. org/10.1016/j.jcpa.2004.09.008> <PMid:15737344>

Kothalawala H., Toussaint M.J. \& Gruys E. 2006. An overview of swine influenza. Vet. Quart. 28(2):46-53.<http://dx.doi.org/10.1080/01652176.2006.96 95207><PMid:16841566>

Lyoo K.S., Kim J.K., Jung K., Kang B.K. \& Song D. 2014. Comparative pathology of pigs infected with Korean H1N1, H1N2, or H3N2 swine influenza A viruses. Virol. J.11(1):170.<http://dx.doi.org/10.1186/1743-422X-11-170> $<$ PMid:25253051>

Mastin A., Alarcon P., Pfeiffer D., Wood J., Williamson S., Brown I., Wieland B. \& COSI Consortium. 2011. Prevalence and risk factors for swine influenza virus infection in the English pig population. PLoS Currents 3:RRN1209. <http://dx.doi.org/10.1371/currents.RRN1209><PMid:21637347>

Meseko C., Olaleye D.I., Capua I. \& Cattoli G. 2013. Swine Influenza in SubSaharan Africa: current knowledge and emerging insights. Zoonoses Publ. Health 61(4):229-237. <http://dx.doi.org/10.1111/zph.12068> $<$ PMid:23826898>

Nakajima N., Sato Y., Katano H., Hasegawa H., Kumasaka T., Hata S., Tanaka S., Amano T., Kasai T., Chong J.M., Iizuka T., Nakazato I., Hino Y., Hamamatsu A., Horiguchi H., Tanaka T., Hasegawa A., Kanaya Y., Oku R., Oya T. \& Sata T. 2012. Histopathological and immunohistochemical findings of 20 autopsy cases with 2009 H1N1 virus infection. Mod. Pathol. 25(1):1-13. <http:// dx.doi.org/10.1038/modpathol.2011.125><PMid:21874012>

Njabo K.Y., Fuller T.L., Chasar A., Pollinger J.P., Cattoli G., Terregino C., Monne I., Reynes J.M., Njouom R. \& Smith T.B. 2012. Pandemic A/H1N1/2009 influenza virus in swine, Cameroon, 2010. Vet. Microbiol. 156(1/2):189192. <http://dx.doi.org/10.1016/j.vetmic.2011.09.003><PMid:21963416>

Pereda A., Cappuccio J., Quiroga M.A., Baumeister E., Insarralde L., Ibar M., Sanguinetti R., Cannilla M.L., Franzese D., Cabrera O.E.E., Craig M.I., Rimondi A., Machuca M., Debenedetti R.T., Zenobi C., Barral L., Balzano R., Capalbo S., Risso A. \& Perfumo C.J. 2010. Pandemic (H1N1) 2009 outbreak on pig farm, Argentina. Emerg. Infect. Dis. 16(2):304-307.<http://dx.doi. org/10.3201/eid1602.091230><PMid:20113566>

Rajão D.S., Couto D.H., Gasparini M.R., Costa A.T.R., Reis J.K.P., Lobato Z.I.P., Guedes R.M.C. \& Leite R.C. 2013. Diagnosis and clinic-pathological findings of influenza virus infection in Brazilian pigs. Pesq. Vet. Bras. 33(1):30-36. <http://dx.doi.org/10.1590/S0100-736X2013000100006>

Schaefer R., Rech R.R., Silva M.C., Gava D. \& Ciacci-Zanella J.R. 2013. Orientações para o diagnóstico de influenza em suínos. Pesq. Vet. Bras. 33(1):61-73. <http://dx.doi.org/10.1590/S0100-736X2013000100012>

Sreta D., Kedkovid R., Tuamsang S., Kitikoon P. \& Thanawongnuwech R. 2009. Pathogenesis of swine influenza virus (Thai isolates) in weanling pigs: an experimental trial. Virol. J. 6(1):34. <http://dx.doi.org/10.1186/1743422X-6-34> <PMid:19317918>

Stärk K.D.C., Pfeiffer D.U. \& Morris R.S. 1998. Risk factors for respiratory diseases in New Zealand pig herds. New Zealand Vet. J. 46(1):3-10.<http:// dx.doi.org/10.1080/00480169.1998.36043><PMid:16032003>

Valheim M., Gamlem H., Gjerset B., Germundsson A. \& Lium B. 2011. Pathological findings and distribution of pandemic Influenza A (H1N1) 2009 virus in lungs from naturally infected fattening pigs in Norway. Influenza Res. Treat. 2011:565787. <http://dx.doi.org/10.1155/2011/565787> $<$ PMid:23074657>

Van Alstine W.G. 2012. Respiratory System, p.348-362. In: Zimmerman J., Karriker L., Ramirez A., Schwartz K.J. \& Stevenson G.W (Eds), Disease of Swine. 10th ed. Iowa State University Press, Ames. 
Van Reeth K., Brown I.H. \& Olsen C.W. 2012. Influenza virus, p.557-571. In: Zimmerman J.J., Karriker L.A., Ramirez A., Schwartz K.J. \& Stevenson G.W. (Eds), Diseases of Swine. 10th ed. Iowa State University Press, Ames.

Vincent A., Awada L., Brown I., Chen H., Claes F., Dauphin G., Donis R., Culhane M., Hamilton K., Lewis N., Mumford E., Nguyen T., Parchariyanon S., Pasick J., Pavade G., Pereda A., Peiris M., Saito T., Swenson S., Van Reeth K., Webby R., Wong F. \& Ciacci-Zanella J. 2014. Review of influenza A virus in swine worldwide: a call for increased surveillance and research. Zoonoses Publ. Health 61(1):4-17.<http://dx.doi.org/10.1111/zph.12049><PMid:23556412>

Watanabe T.T.N., Almeida L.L., Wouters F., Wouters A.T.B., Zlotowski P. \& Driemeier D. 2012. Histopathological and immunohistochemical findings of swine with spontaneous influenza A infection in Brazil, 2009-2010. Pesq. Vet. Bras. 32(11):1148-1154. <http://dx.doi.org/10.1590/S0100736X2012001100013>

WHO 2009. Pandemic (H1N1) 2009 in the African region: update 49. World Health Organization. Disponível em <http://reliefweb.int/report/algeria/ pandemic-h1n1-2009-african-region-update-49> Acesso em 14 nov. 2016.

Zlotowski P., Corrêa A.M.R., Barcellos D.E.S.N., Cruz C.E.F., Asanome W., Barry A.F., Alfieri A.A. \& Driemeier D. 2008. Intestinal lesions in pigs affected with postweaning multisystemic wasting syndrome. Pesq. Vet. Bras. 28(6):313318. <http://dx.doi.org/10.1590/S0100-736X2008000600009> 